\title{
Optimal Pricing of Mail in the Transactional Market and Welfare for the Wider Communications Market ${ }^{1}$
}

\author{
Philippe De Donder ${ }^{\gamma}$, Helmuth Cremer $^{\Sigma}$, Paul Dudley ${ }^{¥}$, Frank Rodriguez ${ }^{\Phi}$
}

\section{INTRODUCTION}

The traditional bulk mail market can be thought of as serving business communication needs with other businesses and customers, and includes transactional and advertising mail, as distinct from single piece mail. Through transactional mail the sender is able to meet its obligation of providing information to the recipient (examples including banks' statements and utilities' invoices). However, transactional mail can also be seen as one of several alternative media for financial institutions to communicate to their customers. Within this wider communications market, the financial institutions can and have started to develop internal profit centers in Europe to charge for their transactional activities. Such centers may form only one part of financial institutions' overall profits and are investigated alongside the need for the universal service provider to break even and therefore within a wider communications market than just the mails' market (but not within an even wider context of the financial institutions' overall profits).

In recent years mail volumes have declined within single piece and bulk mail and while this is in part a consequence of the economic downturn, it is also due to the substitution of mail by other communication media. Single piece (SP) mail has been substituted by texting and email; advertising or direct mail (DM) has been substituted by alternative electronic communication; and transactional or non direct mail (NDM) has been substituted by statements and invoices conveyed by e-mail or over the internet. Our particular focus is on the senders of NDM-transactional items from financial institutions (which we subsequently refer to as 'banks') sending statements.

Following on from previous literature relating to optimal pricing within a global price cap and pricing (De Villemeur et al 2002, 2003; De Donder et al. 2006, 2008), in De Donder et al. (2011a) we developed a model to look at how a monopoly universal service provider (USP) can enhance welfare and break even if it can differentiate between the prices it charges

\footnotetext{
${ }^{\gamma}$ Professor of Economics, Toulouse School of Economics (IDEI \& GREMAQ-CNRS)

${ }^{\Sigma}$ Professor of Economics, Toulouse School of Economics (IDEI \& GREMAQ)

${ }^{¥}$ Head of Regulatory Economics, Royal Mail Group

${ }^{\Phi}$ Associate, Oxera.
} 
for DM and NDM, where the demand functions for the two segments differ as represented by distinct price elasticities, but the marginal costs of the mailings are the same. We then introduced competition from another medium within the DM-advertising segment, and from postal entrants accessing the USP's network downstream and calibrated the model to derive illustrative results in terms of welfare and pricing where the DM and NDM price elasticities are assumed to differ, in line with empirical evidence. In De Donder et al. (2011b) we extended this analysis by looking at the optimal pricing and welfare implications, under alternative pricing conditions introduced by business strategies or regulatory constraints, for the USP and entrants. In these papers, and calibrated illustrations reflective of the postal sector, the NDM contributed significantly to the recovery of the fixed costs of meeting the universal service obligation, through differential pricing between NDM and DM by the USP.

In this paper we look at the effects on welfare and pricing of introducing an electronic alternative to the USP's NDM service. We proceed with the economic model developed in De Donder et al. (2011a and 2011b), with independent mail segments for SP, DM and NDM and alternative media competing with DM and NDM. We focus attention on representative senders of NDM, or banks, who are charged an input price by suppliers for the provision of transactional services and charge a final price on to their customers, for mail and the alternative medium. Our focus throughout is on the impact of an alternative medium to NDM on pricing and economic welfare and so, for ease of exposition and unlike De Donder et al (2011a and 2011b), we do not introduce the possibility of entrants into the postal market. While such an extension would be quite feasible, we consider that it would complicate our results without adding much to the insights gained from the development of our earlier model.

In our initial analysis we assume that a social planner sets the input (producer) and final (consumer) prices to maximize welfare. Subsequently we analyze the results assuming that the banks profit maximize within their profit centers for statements in setting their consumer prices in the NDM-transactional segment. We assume banks' customers switch on price not only between paper and electronic statements but also between banks - with the social planner then setting other prices for postal products to maximize welfare. Finally, we consider the consequences of a binding price cap on the USP's SP price within the main calibrations and some sensitivity analysis.

In Section 2 we summarize the model. In Section 3 we describe the model calibration used. We show the results of our analysis when the social planner sets all prices in Section 4 and then in Section 5 when the social planner sets only the USP prices and the banks set their prices to maximize profit within their profit centers for statements. In Section 6 we conclude.

\section{THE MODEL}

The universal service provider (USP) provides both single piece mail (SP) and bulk mail (BM). We consider two types of BM: direct mail (DM) and non-direct mail (NDM). The demands for the three types of mail (SP, DM and NDM) are assumed to be independent from each other.

The USP has a de facto monopoly on SP mail and faces the demand function $x\left(p^{x}\right)$, where $x$ stands for SP mail quantity and $p^{x}$ for its unit price. Both types of BM face competition from alternative media. We start by describing the market for DM. We denote by $z^{I}$ the quantity of DM sold by the USP, and by $p_{I}^{z}$ its unit price. DM faces the competition of an alternative 
medium whose unit price is $p_{A}^{z}$ and total quantity $z_{A}$. Both types of goods are imperfect substitutes, so that the demand for the USP's DM is given by $z_{I}\left(p_{I}^{z}, p_{A}^{z}\right)$ while the demand for the alternative medium is $z_{A}\left(p_{I}^{z}, p_{A}^{z}\right)$.

NDM is transactional mail, and is sold by the USP to intermediaries or banks. These banks make use of this product to send information to their final clients. They also use alternative electronic media. Banks buy NDM from the USP at a unit price of $p_{I}^{y}$, and alternative medium at a unit price of $p_{A}^{y}$ (which may be nil). Banks then sell both forms of transactional media to their own final customers, at consumer prices equal to $q_{I}^{y}$ for mail, and $q_{A}^{y}$ for the electronic form. Final customers decide how much of these two imperfect substitutes they want to buy. The demand for the USP's NDM is given by $y_{I}\left(q_{I}{ }^{2}, q_{A}^{z}\right)$ while the demand for the electronic alternative to NDM is $y_{A}\left(q_{I}^{z}, q_{A}^{z}\right) .^{2}$

The USP faces a fixed cost of $F$, and constant marginal upstream (collection, sorting) and downstream (delivery) costs of, respectively, $c_{x}$ and $d_{x}$ for SP and $c_{I}$ and $d_{I}$ for (the two types of) BM. The unit cost of the alternative medium to DM is denoted by $c^{z}$, and for the electronic alternative to NDM by $c^{y}$.

To sum up, the profit function of the USP is given by

$$
\Pi_{I}=\left(p_{x}-c_{x}-d_{x}\right) x\left(p_{x}\right)+\left(p_{I}^{z}-c_{I}-d_{I}\right) z_{I}\left(p_{I}^{z}, p_{A}^{z}\right)+\left(p_{I}^{y}-c_{I}-d_{I}\right) y_{I}\left(q_{I}^{y}, q_{A}^{y}\right)-F
$$

while the profit function for the transactional services of a bank (as a representative sender of NDM) is given by

$$
\Pi_{B}=\left(q_{I}^{y}-p_{I}^{y}\right) y_{I}\left(q_{I}^{y}, q_{A}^{y}\right)+\left(q_{A}^{y}-p_{A}^{y}\right) y_{A}\left(q_{I}^{y}, q_{A}^{y}\right)
$$

In section 4, the social planner sets all producer and consumer prices to maximize welfare. In section 5, banks choose their profit-maximizing consumer prices $\left(q_{I}^{y}, q_{A}^{y}\right)$ as a function of ( $\left.p_{I}^{y}, p_{A}^{y}\right)$, and the planner anticipates this move when setting its prices. Moreover, we make explicit that the extent to which banks are able to charge a mark-up over these input costs when pricing transactional media depends on the degree of competition in the banking sector, measured by the number of banks. We attain this objective by modeling the market for transactional media as a Cournot game between $n$ banks (see Appendix). Since the modeling of the whole banking sector is beyond the scope of this paper, we take a partial equilibrium approach, assuming that all (price and non-price) determinants of the demand for transactional media used by banks are exogenously set and constant, so that we concentrate on how $\left(q_{I}^{y}, q_{A}^{y}\right)$ affects this demand. In all cases, we impose that the USP breaks even.

\section{CALIBRATION}

Both our model and initial calibrations are the same as those of De Donder et al. (2011a and 2011b), which applied linear demand functions and commenced from a monopoly USP. The assumptions are not from a particular postal operator, but are reflective, in our view, of the general nature of postal markets and cost structures found in published empirical studies. 
As in our previous studies in De Donder et al. (2011a and 2011b) we commence from the hypothetical situation where the USP faces no competition. The USP sets a price $p^{x}$ of $€ 0.50$ for the single piece product and a price of $€ 0.40$ for $\operatorname{DM}\left(p_{I}^{z}\right)$ and $\operatorname{NDM}\left(p_{I}^{y}\right)$. Total quantities sold at those prices are $x=2$ billion, $z_{I}=2$ billion and $y_{I}=6$ billion items, respectively. The direct own price elasticities are -0.2 for single piece, -1.0 for DM and -0.2 for NDM. ${ }^{3}$ We calibrate linear demands based on these quantities, prices and elasticities.

We need further information to calibrate the demand functions for DM and NDM products when one alternative medium competes with DM and another alternative medium competes with NDM. We use two types of information: the extent of entry for different price configurations and the substitutability between the products within the DM-advertising segment and the NDM-transactional segment (which ultimately includes the products of the USP and an alternative medium in both market segments). For DM, we define the measurement unit for the alternative medium such that one "item" of alternative medium refers to the quantity of this medium that is necessary to have the same response rate as one item of $\mathrm{DM}^{4}$ We then assume that the alternative medium's market share is $25 \%$ if $50 \%$ cheaper than the USP and 35\% if 75\% cheaper than the USP. For NDM, we assume one item of the alternative medium corresponds to one item of mail. We do not have data to calibrate the switching between the USP and alternative medium and so illustrate by reference to the prices to final customers, $q_{I}^{y}$ and $q_{A}^{y}$, such that the alternative medium's market share is $20 \%$ if $q_{I}^{y}$ and $q_{A}^{y}$ are both zero (e.g. if the banks do not charge for the mail or internet item) and $40 \%$ when $q_{I}^{y}=€ 0.40$ and $q_{A}^{y}$ is zero (e.g. if the banks charge the initial calibrated price of the USP for each mail item and zero for each item of the alternative electronic medium). On substitution, we assume the displacement ratio of mail transferring to the alternative medium in NDM or DM is $0.9 .{ }^{5}$ Thereby, the USP products and alternative medium are assumed to be imperfect substitutes.

The USP unit upstream cost is equal to $€ 0.18$ for SP $\left(c^{x}\right)$ and $€ 0.12\left(c^{I}\right)$ for the mail items in DM and NDM. ${ }^{6}$ The USP delivery cost is $€ 0.12$ for all mail items $\left(d^{x}=d^{I}\right)$. Hence the endto-end unit costs are the same for the USP's mail products in DM and NDM. The value of the fixed costs, $F$, equals $€ 1.680 \mathrm{bn}$ so that the USP breaks even in the hypothetical monopoly situation (without any alternative media). We assume the cost of the alternative medium for $\mathrm{DM}, c^{z}$, is $€ 0.20$ per item and, for simplicity, zero for $\operatorname{NDM}\left(c^{y}\right)$.

These assumptions determine the linear demand functions and costs for the calibrated model consistent with the analytical presentation in this paper.

\section{RESULTS WHEN THE SOCIAL PLANNER SETS ALL OF THE PRICES}

We set out below the results of the calibrated model, starting with the case developed in De Donder et al (2011b) with an alternative medium introduced for DM but without a NDM alternative medium. In Table 1 we show the results where the social planner is assumed to set all of the producer and consumer prices to maximize welfare subject to the USP breaking even and discuss this further below.

\section{USP with different prices in DM and NDM and competition to DM from an alternative} medium 
The first column of figures in Table 1 reflects the results shown in De Donder et al. (2011b) for the second-best (Ramsey) solution ${ }^{7}$ with differentiated prices $p_{I}^{y}$ and $p_{I}^{z}$ and competition in DM from an alternative medium. The USP charges $€ 0.539$ for SP, $€ 0.431$ for NDM and $€ 0.274$ for DM with the price of the DM alternative medium assumed to be $€ 0.200$. The USP breaks even reasonably easily with a value for the Lagrange multiplier of the USP profitconstraint of 0.107 and with the profit contributions of $€ 0.470 \mathrm{bn}$ for SP, $€ 1.128 \mathrm{bn}$ for NDM and $€ 0.082 \mathrm{bn}$ for DM offset by the fixed cost of $€ 1.68 \mathrm{bn}$. The NDM product makes the largest single contribution to break even for the USP, and this is also reflected in it providing the most significant contribution to net consumer surplus. Consequently, NDM features prominently in the welfare analysis and financial position of the USP.

\section{Competition to NDM from an alternative medium with producer and consumer prices equal for mail}

The second column of figures shows the second best prices when there are alternative media to both DM and NDM and the banks' consumer price $\left(q_{I}^{y}\right)$ and the producer price $\left(p_{I}^{y}\right)$ are the same in the mails segment of NDM (such that $q_{I}^{y}=p_{I}^{y}$ ). This is akin to a form of regulation on the banks that limits the resale price for mail to be the same as that charged to it by the USP. The SP price $\left(p^{x}\right)$ and NDM prices $\left(q_{I}^{y}, p_{I}^{y}\right)$ are higher (and DM prices the same). The Lagrange multiplier of the USP break-even constraint is also higher at 0.189 as the introduction of the NDM alternative medium makes it more difficult for the USP to break even. Nevertheless the USP breaks even, the banks make a total profit of $€ 0.456 \mathrm{bn}$, and both consumer surplus and welfare increase in the presence of the NDM alternative medium for our calibration. ${ }^{8}$

We also observe that, within the NDM segment, the consumer price, $q_{A}^{y}$ (at $0.230 €$ ), is more than the producer price, $p_{A}^{y}$ (equal to the marginal cost at zero) ${ }^{9}$, even though the selling of the NDM medium alternative does not bring revenue to the USP. The positive price of $q_{A}^{y}$ is related to efficiency (since $q_{I}^{y}$ is pushed above marginal cost in order to recover fixed costs, the planner also increases $q_{A}^{y}$ in order not to distort too much the choice between goods $y_{I}$ and $y_{A}$ ), so that the social planner marks up the marginal costs when setting consumer prices for both NDM and the NDM alternative medium.

In addition to the results shown in Table 1, we also considered the effect of an additional constraint where not only the banks' consumer price $\left(q_{I}^{y}\right)$ and the producer price $\left(p_{I}^{y}\right)$ are the same for NDM, but also the banks' consumer price $\left(q_{A}^{y}\right)$ and the producer price $\left(p_{A}^{y}\right)$ are the same for the NDM alternative medium. In this instance, the outcome is the same (as the second column of figures in Table 1) other than $p_{A}^{y}=q_{A}^{y}$ so that the banks make zero profit and its previous profit of $€ 0.456 \mathrm{bn}$ transfers to the provider of the NDM alternative medium.

Table 1: Calibrated results for the USP without and then with an NDM alternative medium

\begin{tabular}{|c|c|c|c|c|}
\hline & & With NDM med & $\mathrm{m}$ alternative & \\
\hline & $\begin{array}{l}\text { Differentiated } \\
\text { NDM/DM } \\
\text { prices, without } \\
\text { NDM medium } \\
\text { alternative }\end{array}$ & $\begin{array}{l}\text { Second best } \\
\text { outcome, with } \\
\text { additional } \\
\text { constraint of } \\
p_{I}^{y}=q_{I}^{y}\end{array}$ & $\begin{array}{l}\text { Second best } \\
\text { outcome, with a } \\
\text { banks' non- } \\
\text { negative profit } \\
\text { constraint }\end{array}$ & $\begin{array}{l}\text { Second best } \\
\text { outcome, with a } \\
\text { banks' zero profit } \\
\text { constraint, with } \\
\text { greater market } \\
\text { share held by }\end{array}$ \\
\hline
\end{tabular}




\begin{tabular}{|c|c|c|c|c|c|}
\hline & & & & & $\begin{array}{l}\text { alternative } \\
\text { medium }\end{array}$ \\
\hline $\begin{array}{l}\text { Prices }(\boldsymbol{\epsilon}): \\
\text { Single piece }\end{array}$ & $n^{x}$ & 0.539 & 0.670 & 0.558 & 0.656 \\
\hline NDM - Mail - USP & $p_{I}^{y}$ & 0.431 & 0.455 & 0.498 & 0.596 \\
\hline NDM - Mail - Banks & $q_{I}^{y}$ & - & 0.455 & 0.405 & 0.321 \\
\hline NDM - Medium - Alternative & $p_{A}^{y}$ & - & 0.000 & 0.000 & 0.000 \\
\hline NDM - Medium - Banks & $q_{\mathrm{A}}^{y}$ & - & 0.230 & 0.219 & 0.181 \\
\hline DM - Mail - USP & $p_{I}^{z}$ & 0.274 & 0.274 & 0.272 & 0.272 \\
\hline DM - Medium - Alternative & $p_{A}^{z}$ & 0.200 & 0.200 & 0.200 & 0.200 \\
\hline Quantities (bn): & & & & & \\
\hline Single piece & $x$ & 1.969 & 1.864 & 1.953 & 1.875 \\
\hline NDM - Mail - USP & $y_{I}$ & 5.907 & 4.051 & 4.255 & 2.631 \\
\hline DM - Mail - USP & $Z_{I}$ & 2.383 & 2.255 & 2.398 & 2.400 \\
\hline Sub-Total & & 10.259 & 8.170 & 8.606 & 6.906 \\
\hline NDM - Medium & $y_{A}$ & - & 1.983 & 1.917 & 4.008 \\
\hline DM - Medium & $Z_{A}$ & 0.272 & 0.309 & 0.268 & 0.268 \\
\hline Total & & 10.531 & 10.462 & 10.791 & 11.182 \\
\hline \multicolumn{6}{|l|}{ Contribution to fixed cost - } \\
\hline Single piece & & 0.470 & 0.690 & 0.504 & 0.667 \\
\hline NDM & & 1.128 & 0.870 & 1.099 & 0.936 \\
\hline DM & & 0.082 & 0.120 & 0.077 & 0.076 \\
\hline Total USP profit ( $(\boldsymbol{G b n}):$ & & 0.000 & 0.000 & 0.000 & 0.000 \\
\hline Medium - Alternative & & - & - & - & - \\
\hline Bank & & - & 0.456 & 0.000 & 0.000 \\
\hline Sum of profits $(€ b n):$ & & 0.000 & 0.456 & 0.000 & 0.000 \\
\hline \multicolumn{6}{|l|}{ Consumer surplus ( $(\boldsymbol{b} b)$} \\
\hline Single piece & & 2.423 & 2.171 & 2.385 & 2.198 \\
\hline NDM & & 5.816 & 6.364 & 6.616 & 10.463 \\
\hline DM & & 0.708 & 0.664 & 0.713 & 0.714 \\
\hline Total & & 8.947 & 9.199 & 9.714 & 13.376 \\
\hline Welfare (Ebn) & & 8.947 & 9.654 & 9.714 & 13.376 \\
\hline Lagrange multiplier & & 0.107 & 0.189 & 0.099 & 0.098 \\
\hline
\end{tabular}

\section{Competition to NDM from an alternative medium with breakeven constraint for the representative bank}

The third column of figures shows the second-best prices when there are alternative media to both DM and NDM and where we lift the constraint that $p_{I}^{y}=q_{I}^{y}$ while ensuring that the banks' profits (as well as the USP's profit) are non negative. For the banks to break even, the social planner sets prices so that the banks subsidize NDM (with $q_{I}^{y}$ less than $p_{I}^{y}$ ) at the expense of the NDM alternative medium (with $q_{A}^{y}$ more than $p_{A}^{y}$ ). Recall that $p_{I}^{y}$ does not affect allocative efficiency, only USP's financial position, and that $p_{A}^{y}$ is not set by the USP but equals zero. In the first best scenario, consumer prices equate to marginal cost, and $p_{I}^{y}$ 
may be set at its marginal cost of $€ 0.24$. When the USP is required to break even, but the banks are not, $p_{I}^{y}$ increases above $q_{I}^{y}$, with the latter remaining set at marginal cost. ${ }^{10}$ When the banks and USP are both required to breakeven, the banks profit from $q_{A}^{y}>p_{A}^{y}=0$ and the social planner looks to reduce $q_{I}^{y}$ to increase mail volumes and increase $p_{I}^{y}$ to contribute to the USP's break even with the banks profit in the NDM alternative medium being offset by the banks loss in NDM. The fact that $q_{I}^{y}<p_{I}^{y}$ while $q_{A}^{y}>p_{A}^{y}$ comes from the asymmetry between the two goods in terms of the USP break even constraint - the USP is not involved in the selling of $y_{A}$ so that it does not affect its break even while for $y_{I}$ the social planner has an incentive to both lower the consumer price ( $q_{I}^{y}$, to stimulate demand) and to increase the producer price $\left(p_{I}^{y}\right)$ to increase the USP's per item revenue.

When compared to the second column of figures, the additional degree of freedom given to the USP allows it to increase the contribution of NDM towards recovering its fixed cost while decreasing both the prices for DM and SP; the constraint that $p^{x}$ is not less than $p_{I}^{y}+0.06 €$ is binding. The Lagrange multiplier is also lower at 0.099 as it is easier for the USP to break even. The banks can charge less for both their services in the NDM-transactional segment and still break even, and the USP can charge more for its NDM service without reducing demand as this is determined by the banks' consumer price. Total volumes, consumer surplus and welfare all increase with the NDM medium alternative for our calibration. ${ }^{11}$

The fourth column of figures shows the second-best prices under the same assumptions other than that there is a greater preference and market share for the NDM alternative medium. We assume that the alternative medium's market share is $50 \%$ if $q_{I}^{y}$ and $q_{A}^{y}$ are both zero (e.g. if the banks do not charge for the mail or internet item) and $70 \%$ when $q_{I}^{y}=0.40 €$ and $q_{A}^{y}$ is zero (e.g. if the banks charge the initial calibrated price of the USP for each mail item and zero for each item over the internet). Comparing the fourth column with the third column of figures in Table 1, the USP's share of the NDM market segment falls from $69 \%$ to $40 \%$ as demand transfers to the alternative medium. The social planner increases USP prices $p^{x}$ and

$p_{I}^{y}$, and reduces $q_{I}^{y}$ such that the banks make a greater loss in NDM. However, this loss is offset by a lower price and greater volume in the NDM alternative medium. While the SP consumer surplus reduces with the rise in SP price, the consumer surplus for the NDMtransactional segment increases with the reductions in consumer prices and the change in calibration. There are relatively small changes in DM-advertising such that its consumer surplus remains largely unaffected. Overall, the USP continues to break even and its ease in doing so remains similar to that with a lower market share for the alternative medium (with a Lagrange multiplier of 0.098). Hence, when the social planner sets the second-best prices within our calibrations and there is a greater preference and market share for the NDM alternative medium, it benefits customers in the NDM-transactional segment at the expense of SP customers, with negligible effect on the USP's ability to reach breakeven.

\section{Implications when the social planner sets all of the prices}

In each second-best case when the social planner sets all of the prices, the producer price for NDM exceeds that for DM, as was the case in De Donder et al (2011b). Indeed, the presence of competition from an alternative medium increases the price differential between NDM and DM for the USP. 
The consumer price for NDM $\left(q_{I}^{y}\right)$ is also greater than its marginal cost and the consumer price for the NDM alternative medium $\left(q_{A}^{y}\right)$ also increases above its (zero) marginal costs. The market distortion in one good (from the mark-up over marginal costs for $q_{I}^{y}$ due to the fixed cost associated with meeting the USO in the mail market) causes a market distortion in the price of substitute good $q_{A}^{y}$. Hence, for efficiency reasons, a value of $q_{I}^{y}$ above marginal cost is accompanied by a value of $q_{A}^{y}$ also above marginal cost in second-best settings - a result that is common to all the second-best cases considered in this paper.

When the social planner sets the second-best prices to maximize welfare subject to the USP breaking even and the consumer and producer prices to be equal in NDM (in the second set of figures in Table 1), we observe the banks make a profit and the USP has greater financial difficulties in the presence of the NDM medium alternative. However, when the social planner sets the second-best prices to maximize welfare (without constraining producer prices to equate to consumer prices) subject to the USP and banks breaking even (in the third and fourth set of figures in Table 1), the banks use their charge for the NDM alternative medium to subsidize their mail activity and enhance welfare - when the marginal cost of the alternative medium is sufficiently low (or, as we assume it to be zero) - and the USP finds it easier to break even because the lower consumer price increases volumes.

The second best optimal prices without a constraint that consumer prices for NDM be equal to producer prices appear preferable to a resale price constraint in NDM (that is, $q_{I}^{y}=p_{I}^{y}$ ) not only in terms of welfare but also for the USP in terms of financial ease in break even, within the calibrations used. Nevertheless it may not be feasible for a social planner to set all of these prices on behalf of the banks and USP. Consequently we consider in the next Section cases when the banks are able to set the consumer prices in order to profit maximize within their profit centers for statements.

\section{RESULTSWHEN THE SOCIAL PLANNER SETS ONLY MAIL PRODUCT PRICES AND BANKS PROFIT MAXIMISE}

In our second set of results, in Table 2, we assume that the banks maximize profits within their profit centers for statements by setting of the consumer prices while the social planner anticipates this reaction when setting the prices for the postal products to maximize welfare. As discussed in Sections 2 and 3, we analyze banks as profit maximizers competing for the transactional services in a Cournot game and we assume that there are a number of $n$ banks (of 10 or infinity) who set the consumer prices $\left(q_{I}^{y}, q_{A}^{y}\right)$. We then consider the same model but with the addition of a price cap on the SP price.

\section{Competition to NDM from an alternative medium with Cournot pricing by the banks}

In the first two columns of Table 2 we show the results consistent with the original assumption of the market share held by alternative medium. When the number of banks increases, the banks reduce their consumer prices $\left(q_{I}^{y}, q_{A}^{y}\right)$ relative to their corresponding producer prices $\left(p_{I}^{y}, p_{A}^{y}\right)$, and profit levels decrease to zero when the industry moves to a competitive fringe ( $\mathrm{n}=$ infinity). Meanwhile, the social planner seeks to minimize the adverse effect on welfare of the banks' ability to charge higher consumer price in mail $\left(q_{I}^{y}\right)$ for lower $n$ by reducing the producer price $\left(p_{I}^{y}\right)$. The lower producer price $\left(p_{I}^{y}\right)$ makes it more 
difficult for the USP to break even and the value of the Lagrange multiplier of the USP break even constraint and prices in SP and DM ( $p^{x}$ and $p_{I}^{z}$ respectively) increase.

We again observe, as in Section 4, the consumer price for the NDM alternative medium $\left(q_{A}^{y}\right)$ in each case is less than the consumer price for mail $\left(q_{I}^{y}\right)$ and each is above their respective marginal costs. This is a feature of second-best outcomes when the revenue from selling one good (NDM) contributes towards recovering the USP fixed cost while the other (NDM alternative medium) does not.

The consumer prices ( $q_{I}^{y}$ and $q_{A}^{y}$ ) decrease as the banks' market power decreases with higher $n$ and they apply a lower mark-up over marginal costs. For the alternative medium to NDM, the marginal cost is zero so that $q_{A}^{y}$ decreases with higher $n$. For NDM, the banks' marginal cost (which equals producer price) $p_{I}^{y}$ is controlled by the social planner. Anticipating a lower mark-up on $q_{I}^{y}$, the social planner sets a higher $p_{I}^{y}$ (since there is less need to keep $p_{I}^{y}$ low in order to prevent the banks from setting $q_{I}^{y}$ too high). We then have a smaller mark-up on $p_{I}^{y}$ and lower $q_{I}^{y}$ as $n$ increases. Hence the direct effect of a larger $n$ (a smaller mark-up on the banks' marginal cost $p_{I}^{y}$ ) is greater than the indirect effect (the social planner reacts by increasing $\left.p_{I}^{y}\right)$, resulting in lower consumer prices $q_{I}^{y}$ and $q_{A}^{y}$ and enhanced welfare.

In fact, the social planner faces a conflict as it tries both to induce consumer prices $q_{I}^{y}$ and $q_{A}^{y}$ which do not distort too much the relative market shares between the two goods (for productive efficiency) and to drive the producer prices down towards marginal costs (for allocative efficiency). The consumer prices $\left(q_{I}^{y}\right.$ and $q_{A}^{y}$ ) diverge as the mark ups decline. When $n$ is infinite (a competitive fringe), the banks have no market power, such that $q_{I}^{y}=p_{I}^{y}$ and $q_{A}^{y}=p_{A}^{y}$. The social planner controls $p_{I}^{y}$ but not $p_{A}^{y}$, which is set exogenously (by banks' providers of electronic services) to zero (and $p_{A}^{z}$ is set to $€ 0.20$ ). In this limit case, $q_{A}^{y}=0$, while $q_{I}^{y}>0$. The social planner would like to increase $p_{A}^{y}$ from zero, increase $p_{I}^{y}$ and decrease $p^{x}$. The large gap between $q_{A}^{y}$ and $q_{I}^{y}$ with a large $n$ is then caused by $q_{A}^{y}$ being constrained to be zero.

Hence, greater competition in the banking sector for transactional statements reduces the financial pressure on the USP and increases welfare in the presence of a NDM medium alternative. Conversely, mark ups and profit for the banks from transactional statements increase with lower $n$, and cause the USP greater financial pressures. While the USP charges lower prices for NDM, its prices for SP and DM increase and overall consumer surplus and welfare reduces.

Table 2: $\quad$ Calibrated results for the USP with an NDM alternative medium and profit maximizing of transactional statements by the banks

\begin{tabular}{|l|l|l|c|c|c|}
\hline & & \multicolumn{2}{|l|}{$\begin{array}{l}\text { Number of banks with original } \\
\text { assumption of the market share } \\
\text { held by alternative medium }\end{array}$} & \multicolumn{2}{|l|}{$\begin{array}{l}\text { Number of banks, with greater } \\
\text { market share held by alternative } \\
\text { medium }\end{array}$} \\
\cline { 3 - 6 } & & $\mathbf{n = 1 0}$ & $\mathbf{n}$ =infinity & $\mathbf{n = 1 0}$ & $\mathbf{n}=$ infinity \\
\hline $\begin{array}{l}\text { Prices }(\epsilon): \\
\text { Single piece }\end{array}$ & $p^{x}$ & 0.884 & 0.818 & 1.082 & 1.047
\end{tabular}




\begin{tabular}{|c|c|c|c|c|c|}
\hline NDM - Mail - USP & $p_{I}^{y}$ & 0.390 & 0.406 & 0.391 & 0.400 \\
\hline NDM - Mail - Banks & $q_{I}^{y}$ & 0.573 & 0.406 & 0.574 & 0.400 \\
\hline NDM - Medium - Alternative & $p_{A}^{y}$ & 0.000 & 0.000 & 0.000 & 0.000 \\
\hline NDM - Medium - Banks & $q_{\mathrm{A}}^{y}$ & 0.243 & 0.000 & 0.367 & 0.000 \\
\hline DM - Mail - USP & $p_{I}^{z}$ & 0.324 & 0.315 & 0.353 & 0.348 \\
\hline DM - Medium - Alternative & $p_{A}^{Z}$ & 0.200 & 0.200 & 0.200 & 0.200 \\
\hline \multicolumn{6}{|l|}{ Quantities (bn): } \\
\hline Single piece & $x$ & 1.693 & 1.745 & 1.535 & 1.562 \\
\hline NDM - Mail - USP ${ }^{12}$ & $y_{I}$ & 3.456 & 3.718 & 1.798 & 1.936 \\
\hline DM - Mail - USP & $Z_{I}$ & 2.250 & 2.516 & 1.857 & 1.891 \\
\hline Sub-Total & & 7.399 & 7.979 & 5.190 & 5.389 \\
\hline NDM - Medium & $y_{A}$ & 2.250 & 2.516 & 4.091 & 4.516 \\
\hline DM - Medium & $Z_{A}$ & 0.368 & 0.350 & 0.422 & 0.413 \\
\hline Total & & 9.684 & 10.440 & 9.703 & 10.318 \\
\hline \multirow{2}{*}{\multicolumn{6}{|c|}{$\begin{array}{l}\text { Contribution to fixed cost - } \\
\left.\text { USP ( } \epsilon_{b n}\right) \text { : }\end{array}$}} \\
\hline & & & & & \\
\hline Single piece & & 0.989 & 0.905 & 1.200 & 1.167 \\
\hline NDM & & 0.519 & 0.617 & 0.271 & 0.309 \\
\hline DM & & 0.172 & 0.158 & 0.209 & 0.203 \\
\hline Total USP profit (€bn): & & 0.000 & 0.000 & 0.000 & 0.000 \\
\hline Medium - Alternative & & - & - & - & - \\
\hline Bank & & 1.178 & 0.000 & 1.830 & 0.000 \\
\hline Sum of profit (€bn): & & 1.178 & 0.000 & 1.830 & 0.000 \\
\hline \multicolumn{6}{|l|}{ Consumer surplus ( $(\boldsymbol{G b n})$} \\
\hline Single piece & & 1.791 & 1.904 & 1.472 & 1.526 \\
\hline NDM & & 5.891 & 7.069 & 9.149 & 11.053 \\
\hline DM & & 0.598 & 0.618 & 0.542 & 0.552 \\
\hline Total & & 8.280 & 9.590 & 11.163 & 13.130 \\
\hline Welfare (Ebn) & & 9.459 & 9.590 & 12.993 & 13.130 \\
\hline Lagrange multiplier & & 0.381 & 0.312 & 0.688 & 0.619 \\
\hline
\end{tabular}

In the final two columns of Table 2 (and as in Table 1), we show the impact of a greater preference by consumers and thus market share for the alternative medium. ${ }^{13}$ The USP increases all its prices to recover its costs with the banks charging a similar price for mail $\left(q_{I}^{y}\right.$ ), but higher price for the alternative medium $\left(q_{A}^{y}\right)$. While the USP breaks even it has significantly greater difficulty in doing so. Meanwhile the banks raise greater profits at a lower $n$. Hence, when there is a greater preference and market share for the NDM alternative medium, this benefits the banks and NDM-transactional customers at the expense of SP and DM-advertising customers, and makes it more difficult for the USP to break even.

When compared to the results in Table 1, the profit maximizing behavior of the banks causes the USP greater financial difficulty and the SP price rises. Consequently we consider the case where the USP's SP price $p^{x}$ is capped at $€ 0.75$, and binding within our calibrations.

Competition to NDM from an alternative medium, with Cournot pricing by the banks and a price cap on single piece mail. 
When we introduce a price cap of $€ 0.75$ on $p^{x}$, the USP prices $\left(p_{I}^{y}, p_{I}^{z}\right)$ and consumer price for NDM $\left(q_{I}^{y}\right)$ increase, while the other prices $\left(p_{A}^{y}, q_{A}^{y}\right.$ and $\left.p_{A}^{z}\right)$ are unaffected. In fact, the cap on SP causes the consumer prices in both DM-Advertising and NDM-transactional to increase, with the exception of $q_{A}^{y}$ (which is a function of $n$ and of $p_{A}^{y}(=0)$ only).

With the price cap on SP, the consumer prices $q_{A}^{y}$ and $q_{I}^{y}$ remain decreasing in $n$, but $p_{I}^{y}$ decreases in $n$ (whereas, as reported in Table 2, $p_{I}^{y}$ increased in $n$ without the cap on $p^{x}$ ). The price cap causes the USP greater financial difficulty in breaking even, as reflected in higher values of the Lagrange multiplier, and higher price $p_{I}^{y}$ relative to those in Table 2 . The social planner would still like to charge a lower $p_{I}^{y}$ to offset higher consumer prices for lower $n$, but the need for the USP to break even overrides this and leads to increases in $p_{I}^{y}$ relative to those in Table 2. We also observe that $p_{I}^{y}$ rises more than $p_{I}^{z}$, because of the difference in price elasticity, thereby increasing the price differential between NDM and DM.

The increase in $q_{I}^{y}$ leads to lower consumer surplus and welfare with the introduction of the cap on $p^{x}$. The price cap leads to an increase in consumer surplus for SP and reduction in consumer surplus for the NDM-transactional and DM-advertising segments. The net effect is a reduction in welfare which is greater where the cap acts as a more significant constraint; that is, when $n$ is low.

When we extend this further and assume a greater preference and market share for the alternative medium, ${ }^{14}$ the USP looks to increase all its prices but fails to break even for each n. The banks set higher consumer prices $\left(q_{I}^{y}\right.$ and $\left.q_{A}^{y}\right)$ to maintain a constant share for NDM on the NDM-transactional segment and the scale of the banks profit exceeds the USP's loss for $\mathrm{n}$ in excess of 10, but less then infinity - raising the possibility of part of the banks' profit being used to help fund the USP's loss.

\section{CONCLUSIONS}

Financial institutions might look to make statement information profit centers for their businesses. While there are some social obstacles to implementing such an approach, with customers used to access to information without any charge, the charging of statements is beginning and may continue. In this paper we have looked at the implications of such institutions paying USPs and an alternative medium for the provision of such services, and recharging them to the customer.

Our focus has been on the NDM-transactional segment where there is imperfect competition between paper statements delivered by the USP and electronic statements provided by an electronic alternative. We have looked at this through an extension to the economic model of De Donder et al. (2011a and 2011b) by focusing on the welfare and pricing implications of imperfect competition between the USP and alternative media in NDM-transactional and DM-advertising. In each case, the USP continues to differentiate the prices of its NDM and DM services to reflect different price elasticities assumed for the two markets.

In section 4, we considered the case where a social planner sets the producer and consumer prices (other than those assumed to be constant) to maximize welfare. When only the USP is 
assumed to break even, the banks activities might not be profitable. If the banks charge a resale price for paper statements equal to the producer price from the USP, then the banks might be profitable provided that the sale of their electronic statements is priced above its marginal cost. However, within our calibrations, it is welfare enhancing for the social planner to set consumer prices differing from producer prices and such that both the USP and banks breakeven. In this case the profits to the banks from the electronic statements subsidize a lower consumer price (stimulating growth) and a loss to the banks for paper statements.

Subsequently, in section 5, we considered the case where the banks profit maximize in setting their consumer prices in the NDM-transactional market - using mark ups of producer prices ( $\left.p_{I}^{y}, p_{A}^{y}\right)$ to consumer prices $\left(q_{I}^{y}, q_{A}^{y}\right)$ determined by the degree of competition assumed for the $n$ banks' transactional services - with the social planner then setting other prices for postal products to maximize welfare. In the absence of any price cap on SP, the USP is able to break even, within our calibrations, but with lower consumer surplus and welfare than before. In the presence of a price cap on SP, the USP is under greater financial pressure and not able to break even when the calibrations are amended to reflect a greater preference and market share for the electronic medium, while the banks make substantial profits from charging their customers for transactional services. In such circumstance, where banks charge their customers for transactional services and rely on the USP's network for provision of their mail services and there is a public policy objective to limit the price of SP, part of the banks' profit from transactional statements might be used to help fund the deficit to the USP.

We conclude that the introduction of an alternative medium for NDM, in addition to DM, has the potential to enhance welfare, if the USP and banks' profit centers relating to statements could be regulated to breakeven. Alternatively, if the banks profit maximize its profit centers for statements, then it might lead to increased financial pressure on the USP, and particularly so if there is either a binding price cap regulation on the USP or significant changes in customer behavior in switching to an electronic medium. This could result in the USP being unable to breakeven at which point some means of funding the universal service provision would need to be considered. Within our model, there is no scope to raise funds through charging postal entrants, but there could be scope to raise funds through general taxation, taxation on the banks' relevant profit centers from transactional statements or through charges for the alternative electronic medium - though not currently envisaged within the current (Third) European Postal Services Directive. This brings to the fore the consideration of public policy and the balance of choices between the consumer demand for the universal service and associated fixed costs of the USP, the incentives and profit maximizing behavior of the banks and the consumer demand for and development of the alternative electronic medium.

\section{NOTE}

\footnotetext{
${ }^{1}$ The analysis contained in this paper reflects the view of the authors and may not necessarily be those of Royal Mail Group.

${ }^{2}$ The demand for transactional media is actually a derived demand, since transactional media are used as inputs by banks. As explained below in the text, we assume that all determinants of this demand other than transactional media prices are held constant, so that we can concentrate on how the demand for transactional media is affected by the price of NDM and its electronic substitutes.

${ }^{3}$ These values are broadly in line, as approximations, with the empirical literature in this area (see, for example, Veruete-McKay et al, 2011).

${ }^{4}$ So, if the alternative medium is email, and if the response rate of prospective customers to email is, say, 20 times less than for DM, then one item of alternative medium corresponds to 20 emails.
} 
${ }^{5}$ This means that nine out of ten items of the alternative medium are displaced BM mail (either DM or NDM as relevant) from the USP, while one in ten are additional volumes created in the sector.

${ }^{6} \mathrm{We}$ add a price constraint that $p^{x}$ is not less than $p_{I}^{y}+0.06 €$.

${ }^{7}$ This corresponds to the prices which maximize total welfare in the economy (measured as the sum of consumer surpluses and firms' profits) under the constraint that the USP breaks even. See De Donder et al (2011b) for the formal statement.

${ }^{8}$ Alternative pricing constraints relating to $y$ could be applied such that $q_{I}^{y}=q_{A}^{y}$ or $q_{A}^{y}=p_{A}^{y}$, where the banks make negative profit, or $p_{I}^{y}=p_{A}^{y}(=0)$ where $y_{I}$ is close to zero within the calibrations. Hence these alternatives are not pursued further.

${ }^{9} \mathrm{An}$ increase in the producer price, $p_{A}^{y}$, transfers the profit of the banks to the provider of the NDM medium alternative when in the range $\left(0, q_{A}^{y}\right)$. Hence the level of the producer price of the alternative medium in NDM only has a distributional effect in allocating the total profit between the banks and provider of the alternative medium.

${ }^{10}$ If the only constraint were rather for the banks to break even, we would get $p_{I}^{y}<q_{I}^{y}$.

${ }^{11} \mathrm{We}$ also considered the effect of an increase in the marginal cost of the alternative medium in NDM above zero. This makes it more difficult for the banks to break even. Consequently, the banks increase their consumer prices. The USP also increases its prices as the total volumes fall and it finds it more difficult to break even.

${ }^{12} \mathrm{We}$ report total quantities across the $n$ banks, hence the uppercase symbols $Y_{I}$ and $Y_{A}$--see Appendix.

${ }^{13}$ The alternative medium's market share is $50 \%$ if $q_{I}^{y}$ and $q_{A}^{y}$ are both zero (e.g. if the banks do not charge for the mail or internet item) and $70 \%$ when $q_{I}^{y}=€ 0.40$ and $q_{A}^{y}$ is zero.

${ }^{14}$ ibid footnote 13 .

\section{APPENDIX: COURNOT COMPETITION BETWEEN BANKS}

In section 5, we consider the following two stage procedure. In the first stage, the USP chooses optimally the producer prices $p^{x}, p_{I}^{y}, p_{I}^{z}$. In the second stage, $n$ banks compete à la Cournot - i.e., each bank simultaneously sets its quantity (of both NDM mail and its alternative medium) in order to maximize its profit, given the quantities chosen by the other $n-1$ firms. Observe that this implies that some final consumers switch from one bank to another when transactional media prices vary between banks. As usual, we solve the game by backward induction - i.e., we assume that the USP perfectly anticipates the Cournot game result when setting its optimal prices.

To model this situation, we proceed to the following change of notation: there are $n$ identical banks, and each bank is represented by the index $i=1,2, \ldots n$. We denote by $y_{I}^{i}$ (resp., $y_{A}^{i}$ ) the quantity of NDM (resp., of alternative medium) sold by bank $i$. We denote by $Y_{I}$ (resp., $Y_{A}$ ) the total quantity of NDM (resp., of alternative medium) sold by the $n$ banks, that is:

$$
Y_{I}=\sum_{i=1}^{n} y_{I}^{i} \text { and } Y_{A}=\sum_{i=1}^{n} y_{A}^{i} .
$$

The inverse demand function for these two goods is then given by

$$
q_{I}^{y}\left(Y_{I}, Y_{A}\right)=\text { and } q_{A}^{y}\left(Y_{I}, Y_{A}\right) \text {. }
$$

The profit of bank $i$ is given by

$$
\pi_{B}^{i}=\left[q_{I}^{y}\left(Y_{I}, Y_{A}\right)-p_{I}^{y}\right] y_{I}^{i}+\left[q_{A}^{y}\left(Y_{I}, Y_{A}\right)-p_{A}^{y}\right] y_{A}^{i},
$$

with total banks' profit given by $\Pi_{B}=\sum_{i=1}^{n} \pi_{B}^{i}$ and the equilibrium of the Cournot game solving

$$
\max _{y_{I}^{i}, y_{A}^{i}} \pi_{B}^{i} \text { for all } i=1,2, \ldots n \text {. }
$$


Finally, note that, since we have assumed identical banks, we have that $Y_{I}=n y_{I}^{i}$ and $Y_{A}=n y_{A}^{i}$ (i.e., each bank sells the same amount of NDM and of its alternative medium).

\section{REFERENCES}

Billette de Villemeur, E, H. Cremer, B. Roy and J. Toledano (2002), “Access and (Non)Uniform Pricing in the Postal Sector", in: Competition transformation of the postal and delivery sector, M.A. Crew and P.R. Kleindorfer, ed., Boston: Kluwer Academic Publications, pp43-68.

Billette de Villemeur, E, H. Cremer, B. Roy and J. Toledano (2003), "Pricing and worksharing discounts in the postal sector", in: Postal and delivery services: delivering on competition, M.A. Crew and P.R. Kleindorfer, ed., Boston: Kluwer Academic Publications, pp43-68.

Cazals C., Veruete-McKay L., Florens J., F Rodriguez and S. Soteri (2011), “UK Letter Mail Demand: A Content-Based Time Series Analysis Using Overlapping Market Survey Statistical Techniques", Reinventing the Postal Sector in the Electronic Age, edited by M.A. Crew and P.R.Kleindorfer, Cheltenham: Edward Edgar, pp 91-108.

De Donder Ph., Cremer H., Dudley P. and Rodriguez F. (2008), "Pricing, Welfare and Organizational Constraints for Postal Operators", Competition and Regulation in the Postal and Delivery Sector, edited by M.A. Crew and P.R.Kleindorfer, Cheltenham: Edward Edgar, pp150-166.

De Donder Ph., Cremer H., Dudley P. and Rodriguez F. (2006), “A welfare analysis of price controls with end-to-end mail and access services", Liberalization of the Postal and Delivery Sector, edited by M.A. Crew and P.R.Kleindorfer, Cheltenham: Edward Edgar, pp307-26.

De Donder Ph., Cremer H., Dudley P. and Rodriguez F. (2011a), "Welfare and Pricing of Mail in a Communications Market", Review of Network Economics, forthcoming De Donder Ph., Cremer H., Dudley P. and Rodriguez F. (2011b), "Optimal pricing for mail and welfare implications in a communications market", Reinventing the Postal Sector in the Electronic Age, edited by M.A. Crew and P.R.Kleindorfer, Cheltenham: Edward Edgar, pp73-90. 